\title{
Mechanism of Chinese Medicinal-Medicated Leaven for Preventing and Treating Gastrointestinal Tract Diseases
}

\author{
Xin $\mathrm{Fu}^{\mathrm{a}}$ Qiuhong Wang ${ }^{\mathrm{b}}$ Haixue Kuang ${ }^{\mathrm{a}}$ Jiang Pinghui ${ }^{\mathrm{c}}$ \\ ${ }^{a}$ School of Pharmacy, Key Laboratory of Chinese Materia Medica of Ministry of Education, Heilongjiang University of \\ Chinese Medicine, Harbin, PR China; ${ }^{b}$ School of Traditional Chinese Medicine, Guangdong Pharmaceutical University, \\ Guangzhou, PR China; ' College of Electrical and Information Engineering, Heilongjiang Institute of Technology, \\ Harbin, PR China
}

\section{Keywords}

Gastrointestinal tract disease - Medicated leaven .

Bacteriostatic action $\cdot$ Secondary metabolites $\cdot$ Immunity

\section{Abstract}

In recent times, there has been an increased attention on gastrointestinal tract (GIT) diseases, with GIT diseases becoming one of the greatest crises to human health. In China, traditional Chinese medicine, Medicated leaven (ML), has been applied to treat gastrointestinal diseases for thousands of years. However, its mechanism remains unclear till date. Here we review both the antibacterial and antiviral effects of ML, the mechanisms for improving human immunity, antioxidant and anti-inflammatory activities, the role of digestive function, and the role of its secondary metabolite. ML may be a new hope for GIT diseases.

cc 2020 S. Karger AG, Basel

Records of medicated leaven (ML) in medicinal theory (Yao xinglun) dates back to 1612 A.D. Indeed, a large number of papers have been published in Chinese jour- nals regarding ML. Also, a few of these articles about ML have been written in English. In fact, it is one of the most important drugs for the treatment of gastrointestinal diseases in China.

Due to the discovery of artemisinin, $\mathrm{Tu}$ Youyou, a phytochemist more than 80 years old at the China Academy of Traditional Chinese Medicine, was awarded the 2011 Lasker-DeBakey Clinical Medical Research Award and the 2015 Nobel Prize in Medicine. Artemisinin as a drug for treating malaria has saved millions of lives in the world, particularly in developing countries $[1,2]$.

ML is composed of six Chinese medicines, including Artemisia annua, Xanthium sibiricum, Polygonum hydropiper, adzuki bean, bitter apricot kernels, and flour. ML is a processed product, obtained from the fermentation of a mixture of fresh Chinese herbs in appropriate temperature and humidity. It contains yeast, vitamin B complex, ergosterol, essential oil (volatile oil), enzymes, glycosides, etc., and inhibits and kills bacteria and viruses and improves the function of the gastrointestinal tract (GIT). How does ML exert this miraculous effect for GIT? 


\section{Antibacterial and Antiviral Effect in GIT}

In ML, A. annua, X. sibiricum, P. hydropiper, which contain the antibacterial active component for GIT, are combined with flour, bitter apricot kernels, and adzuki bean; and this mixture helps in the regulation of gastrointestinal microflora balance. ML is able to inhibit and kill different kinds of bacteria in GIT, such as dysentery bacillus, methicillin-resistant Staphylococcus aureus (MRSA), lemon S. aureus, Escherichia coli, beta hemolytic streptococcus etc [3].

In $A$. annua, the antimalarial property of Artemisinin was discovered by Chinese scientists, which is considered as one of the great discoveries in Medicine in the 20th century. Through inhibiting of toll-like receptors 2 and Nod2 mRNA expressions and nuclear transcription factor kappa B (NF- $\kappa \mathrm{B})$ activation, Artesunate was associated with the reduction on tumor necrosis factor-alpha (TNF- $\alpha$ ) release to mediate protection on septic mice with MRSA [4]. What's more, this increased the antibiotic accumulation within methicillin-resistant MRSA. Artesunate enhances the antibacterial activity of $\beta$-lactams [5]. Dihydroartemisinin and artemether also have antibacterial and antiviral active components in A. annua. The essential oil of $A$. annua has an antipathogenic activity such as gram-positive, gram-negative bacterial strains and yeast strains and can interfere with the expression of cell-associated and soluble virulence factors [6]. There are several active fractions and components exhibiting activity against Clostridium perfringens with different minimum inhibitory concentrations [7]. A. annua L. extracts exhibit antimicrobial activity against the periodontopathic microorganisms Aggregatibacter actinomycetemcomitans, Fusobacterium nucleatum subsp. animalis, F. nucleatum subsp. polymorphum, and Prevotella intermedia [8]. A. annua leaves (AAL) showed significant leishmanicidal activity against Leishmania donovani in vitro and in vivo [9].

In many experiments, $X$. sibiricum showed antibacterial activity against MRSA [10]. In addition, the constituents of $X$. sibiricum Patr er Widd were found to have effective antibacterial activity against methicillinresistant MRSA. In X. sibiricum, the main component xanthatin has an exceptional activity against strains of MRSA [11], xanthinin and xanthatin were found to have antibacterial and cytotoxic activities [12]. Compounds $8,11,12,23$, and 24 were isolated from the fruits of $X$. sibiricum which exhibited potent activity against influenza A virus (A/FM/1/47, H1N1) [13]. Compound 1 of the chemical constituents of the roots of $X$. sibiricum showed moderate antibacterial activity against Bacillus subtilis, E. coli, MRSA, and Micrococcus tetragenus [14].

Early in the 20th century, people were aware that $\mathrm{He}$ licobacter pylori infections can cause gastric cancer and peptic ulcer, and the antimalarial artemisinin from $A$. annua acts remarkably against the pathogen responsible for peptic ulcer diseases, $H$. pylori $[15,16]$.

Methanol and water extracts of bitter kernels had the highest activity, which showed a broad spectrum of antimicrobial activity against gram-negative, gram-positive, and Candida strains. The higher activity of bitter kernels was found for both the methanol and water extracts against $S$. aureus. The methanol extracts of bitter kernels were very potent against the gram-negative bacteria E. coli. Additionally, the methanol extract of bitter apricot kernels had significant anti-Candida albicans activity [17].

Using column chromatography, Confertifolin was isolated from the essential oil of Polygonum hydropiper L. Confertifolin showed activity both in bacteria and fungi including Enterococcus faecalis [18]. Polygodial and (2E)-hexenal possessed antibacterial activity against Salmonella choleraesuis. In this food-borne bacterium at any stage of growth, these $2 \alpha, \beta$-unsaturated aldehydes showed antibacterial activity from the time kill curve study. However, they showed different effects at the stage of growth of S. choleraesuis [19].

Artemisinins can inhibit hepatitis $B$ and $C$ viruses, a range of human herpes viruses [20], HIV-1 [21], influenza virus $A[20,22]$, and a bovine viral diarrhea virus [23] in the low micromolar range. In addition, Artemisinins possessed antibacterial activity against other herpes viruses from all subfamilies ( $\alpha, \beta$, and $\gamma$ ), namely, Epstein-Barr virus, herpes simplex virus 1 , and human herpes virus $6 \mathrm{~A}[24,25]$. Importantly, during preemptive antiviral therapy after stem cell transplantation has been described, this is the first time artesunate was used for the treatment of human cytomegalovirus (HCMV), a drug-resistant infection [27]. Artesunate can reduce the level of NF- $\mathrm{BB}$ and Sp1 in HCMV through inducing protein synthesis and reducing the DNA binding activity of NF- $\mathrm{kB}$ and Sp1 [24]. Its activity is not restricted to human cytomegalovirus (HCMV), but it also includes some animal CMVs, such as rat CMV [25].

Isoquercitrin in $P$. hydropiper suppresses the adipogenesis of 3T3-L1 cells via the inhibition of $\mathrm{Wnt} / \beta$-catenin signaling. $P$. hydropiper and isoquercitrin may therefore be potential therapeutic agents for obesity and its associated disorders [26]. These components produce antibacterial and antiviral effects together (Table 1). 
Table 1. Antibacterial and antiviral effect for GIT

\begin{tabular}{|c|c|c|c|}
\hline Author & Year & No. & Mechanism \\
\hline \multirow[t]{2}{*}{ Wang et al. [3] } & 2009 & ML & $\begin{array}{l}\text { Inhibiting and killing dysentery bacillus, MRSA, lemon Staphylococcus } \\
\text { aureus, Escherichia coli, beta hemolytic streptococcus etc }\end{array}$ \\
\hline & & Artemisia annua & \\
\hline $\begin{array}{l}\text { Efferth et al. [20, 21], } \\
\text { Qian et al. [22], } \\
\text { Romero et al. [23] }\end{array}$ & $2002 / 1982 / 2006$ & Artemisinin & $\begin{array}{l}\text { Inhibiting hepatitis } \mathrm{B} \text { and } \mathrm{C} \text { viruses, human herpes viruses, } \mathrm{HIV}-1 \text {, } \\
\text { influenza virus } \mathrm{A} \text {, a bovine viral diarrhea virus }\end{array}$ \\
\hline $\begin{array}{l}\text { Efferth et al. [24], } \\
\text { Kaptein et al. [25] }\end{array}$ & $2002 / 2006$ & Artemisinin & $\begin{array}{l}\text { Possessing antibacterial activity against other herpes viruses from all } \\
\text { subfamilies }(\alpha, \beta \text {, and } \gamma) \text {, namely, Epstein-Barr virus, herpes simplex } \\
\text { virus } 1 \text {, and human herpes virus } 6 \mathrm{~A}\end{array}$ \\
\hline Li et al. [4] & 2010 & Artesunate & $\begin{array}{l}\text { Inhibiting of TLR } 2 \text { and Nod } 2 \text { mRNA expressions and transcription factor } \\
\text { NF-kappaB activation; reducing TNF-alpha release to mediate protection } \\
\text { of septic mice with MRSA }\end{array}$ \\
\hline Jiang et al. [5] & 2013 & Artesunate & Enhancing antibacterial activity of $\beta$-lactams \\
\hline Shapira et al. [27] & 2008 & Artesunate & Treating for HCMV about drug-resistant infection \\
\hline Efferth et al. [24] & 2002 & Artesunate & $\begin{array}{l}\text { Reducing the level of NF- } \kappa \mathrm{B} \text { and Sp1 in HCMV through inducing protein } \\
\text { synthesis and reducing the DNA binding activity of NF- } \kappa B \text { and Sp1 }\end{array}$ \\
\hline Kaptein et al. [25] & 2006 & Artesunate & Restricting to HCMVs, but also includes some animal CMVs \\
\hline Kim et al. [8] & 2015 & $\begin{array}{l}\text { Artemisia } \\
\text { annua extracts }\end{array}$ & $\begin{array}{l}\text { Restricting to the periodontopathic microorganisms Aggregatibacter } \\
\text { actinomycetemcomitans, Fusobacterium nucleatum subsp. animalis, } \\
\text { Fusobacterium nucleatum subsp. polymorphum, and Prevotella } \\
\text { intermedia }\end{array}$ \\
\hline Islamuddin et al. [9] & 2014 & $\begin{array}{l}\text { Artemisia annua } \\
\text { leaves }\end{array}$ & $\begin{array}{l}\text { Showing significant leishmanicidal activity against Leishmania } \\
\text { donovani in vitro and in vivo }\end{array}$ \\
\hline Marinas et al. [6] & 2015 & The essential oil & $\begin{array}{l}\text { Restricting to gram-positive, gram-negative bacterial strains and yeast } \\
\text { strains and interfering with the expression of cell-associated and soluble } \\
\text { virulence factors }\end{array}$ \\
\hline Cumanda et al. [10] & 1991 & Xanthium sibiricum & Inhibiting the MRSA \\
\hline Tsankova et al. [12] & 1994 & Xanthinin and xanthatin & Showing antibacterial and cytotoxic activities \\
\hline Shi et al. [13] & 2015 & $\begin{array}{l}\text { Compounds } 8,11,12 \text {, } \\
23 \text {, and } 24\end{array}$ & Exhibiting potent activity against influenza A virus (A/FM/1/47, H1N1) \\
\hline Chen et al. [14] & 2015 & Compound 1 & $\begin{array}{l}\text { Inhibiting Bacillus subtilis, Escherichia coli, Staphylococcus aureus and } \\
\text { Micrococcus tetragenus }\end{array}$ \\
\hline \multirow[t]{2}{*}{ Chen et al. [14] } & 2015 & $\begin{array}{l}\text { Compound } 6 \text { and } \\
\text { compound } 12\end{array}$ & $\begin{array}{l}\text { Exhibiting stronger antibacterial activity against } E \text {. coli, with minimum } \\
\text { inhibitory concentration values of } 0.17 \text { and } 0.35 \mu \mathrm{g} / \mathrm{mL} \text {, respectively }\end{array}$ \\
\hline & & Polygonum hydropiper & \\
\hline Duraipandiyan et al. [18] & 2010 & Confertifolin & Showing activity both in bacteria and fungi including Enterococcus faecalis \\
\hline Kubo et al. [19] & 2001 & $\begin{array}{l}\text { Polygodial and } \\
\text { (2E)-hexenal }\end{array}$ & Possessing antibacterial activity against Salmonella choleraesuis \\
\hline Kubo et al. [19] & 2001 & $\begin{array}{l}\text { Two } \alpha, \beta \text {-unsaturated } \\
\text { aldehydes }\end{array}$ & $\begin{array}{l}\text { Showing different inhibited effects at stage of growth of Staphylococcus } \\
\text { aureus }\end{array}$ \\
\hline \multirow[t]{2}{*}{ Lee et al. [26] } & 2011 & Isoquercitrin & $\begin{array}{l}\text { Suppressing the adipogenesis of } 3 \mathrm{~T} 3-\mathrm{L} 1 \text { cells via the inhibition of } \\
\text { Wnt/ } \beta \text {-catenin signaling }\end{array}$ \\
\hline & & Bitter apricot kernels & \\
\hline Shapira et al. [27] & 2008 & $\begin{array}{l}\text { Methanol and } \\
\text { water extracts }\end{array}$ & $\begin{array}{l}\text { Exhibiting antibacterial activity against gram-negative, gram-positive and } \\
\text { Candida strains }\end{array}$ \\
\hline Shapira et al. [27] & 2008 & Methanol extracts & $\begin{array}{l}\text { Inhibiting the gram-negative bacteria } E . \text { coli and significant } \\
\text { anti-Candida albicans activity }\end{array}$ \\
\hline
\end{tabular}




\section{Antioxidant and Anti-Inflammatory Activity}

Free radicals may cause a number of diseases, such as cancer and atherosclerosis [28-30]. And antioxidants can neutralize free radicals, which may be of central importance in the prevention of these diseases [31].

Some flavonoids that are frequent components of the human diet have shown strong antioxidant activities [32]. In fact, higher plants exhibit significant potency against human bacterial and fungal pathogens. A role for oxidative stress suggest that antioxidant defenses act in combination to affect the cellular response to ART in tumor cells [33]. Some isolated flavonoids from the dried leaves of $P$. hydropiper $\mathrm{L}$ possess strong antioxidative capabilities. 2"-O-(3,4,5-trihydroxybenzoyl) quercitrin (Galloyl quercitrin) has the most effective antioxidant activities [34]. Antioxidative flavonoids and flavonoid glucoside were isolated from the leaves of $P$. hydropiper on the basis of chemical and spectroscopic evidence [35]. By various chromatographic methods, some new phenylpropanoid esters which were isolated from the methanolic extract of the whole plant of $P$. hydropiper $\mathrm{L}$ were found to possess effective antioxidant activity [36].

Furthermore, the results show adzuki bean extract is a potential antioxidant [37]. Amygdalin has anti-inflammatory and analgesic effects by suppressing the mRNA expressions of COX-2 and iNOS [38]. Amygdalin may have analgesic property for relieving inflammatory pain, by effectively alleviating responses to lipopolysaccharide (LPS) treatment in RAW 264.7 cells and carrageenan-induced arthritis in rats [39].

A. annua leaf extracts have potent antioxidant activities that significantly inhibit lipid peroxidation and erythrocyte hemolysis [40].

The flavonoids casticin and chrysosplenol D inhibited croton oil-induced ear edema. In addition, casticin and chrysosplenol D inhibited LPS-induced systemic inflammatory response syndrome in mice. LPS-induced release of interleukin- 1 beta (IL-1 $\beta$ ), IL-6, and MCP- 1 could be suppressed by casticin and chrysosplenol D; they inhibited cell migration and in Raw 264.7 cells, reduced LPSinduced I $\mathrm{BB}$ and c-JUN phosphorylation [41]. Through altering of the expression level of flavonoids, biosynthetic pathway genes, the flavonoid content of A. annua can be increased, which enhances the antioxidant and cytotoxic potential of the plant [42].

A. annua L. extract reduces insulin resistance and hepatic steatosis in HFD-fed mice and attenuates connective tissue growth factor and fibrosis-related transform- ing growth factor- $\beta 1$ and HFD-induced collagen deposition [43].

Endotoxin, TNF- $\alpha$, and IL-6 levels were remarkably decreased and protein and mRNA expression of $\alpha$-smooth muscle actin, toll-like receptors 4 , myeloid differentiation factor 88 and transforming growth factor- $\beta 1$ were significantly downregulated by Artesunate (Art). In addition, Artesunate (Art) also significantly inhibited the NF- $\kappa B$ p65 translocation into the nucleus [44]. The various parts of A. annua L., including flowers, leafs, stems, and roots have the polyphenolic profile and antioxidant effects [45]. The acetone extract of $A$. annua L. inhibited prostaglandin E2, LPS-induced nitric oxide, and proinflammatory cytokine (IL-1 $\beta$, IL-6, and IL-10) production. In addition, ethanol extract had the highest free radical scavenging activity [8]. By suppressing Src/Syk/NF- $\kappa B$ and IRAK/ AP-1/CREB pathways, $P$. hydropiper L. showed strong anti-inflammatory activity, which contributed to an antigastritis remedy [46]. Daphniphyllum calycinum Benth and $P$. hydropiper L. extracts can significantly improve the dextran sulfate sodium-induced colitis in mice, reduce myeloperoxidase activity in colonic mucosa and content of IL- $1 \beta$, TNF- $\alpha$, malondialdehyde and nitric monoxide in colonic homogenate [47].

\section{The Role of Immune Function}

Artemisinin and its derivatives can enhance the DNA synthesis of mouse spleen cells, which had been activated with alloantigens or $\mathrm{T}$ cell mitogen Con $\mathrm{A}$ in vitro and in vivo. The results suggested that artemisinin and its derivatives promote $\mathrm{T}$ cell function selectively, and had a potential application for the recovery of immune function [48]. In addition, artesunate with low toxicity had a relatively high immunosuppressive activity and could inhibit T lymphocyte proliferation induced by mitogen and alloantigen. Meanwhile, artesunate could restrain DTH response significantly. Moreover, artesunate could also enhance the secretion of TFG- $\beta$, coupling with the striking increase of NF- $\mathrm{kB} / \mathrm{p} 65$ and Smad2/3 signaling [49]. A monoclonal antibody $(\mathrm{mAb}) 3 \mathrm{H} 2$ had sensitive and specific indirect competitive enzyme-linked immunosorbent assay for artemisinin. The $\mathrm{mAb} 3 \mathrm{H} 2$ recognized dihydroartemisinin, artesunate, and artemether with crossreactivity of 650,57 , and $3 \%$, respectively [50]. Meanwhile, the artemisinin-thyroglobulin conjugate generated polyclonal antibodies [51]. The flavonoids of ALLs can suppress CYP450 enzymes by altering the absorption and metabolism of artemisinin in the body, they have also 
been linked to a beneficial immunomodulatory activity on chronic diseases [52]. Artemether could enhance DTH reaction, and increase the production of hemagglutinating antibody in normal mice. As well, artemether was significantly effective in the depletion of splenic CD4+ CD25+ Foxp3+ Treg cells. Artemether also enhanced the production of IL- 4 and IFN- $\gamma$. So artemether has both cytotoxic and immunomodulatory properties in vivo [53].

After thorough stir-frying as an ingredient, the dried seeds of Xanthium strumarium are used in traditional Chinese medicines for relieving allergy. A compound of them exhibited significant selective inhibition of superoxide anion generation [54]. Xanthatin and xanthinosin, which can inhibit nitric oxide synthesis, restrained the expression of iNOS and COX-2 and the activity of NF-kB through the inhibition of LPS-induced I-kB-alpha degradation [55]. A new antifungal peptide from rice beans suppressed the activity of human immunodeficiency virus type 1 reverse transcriptase and inhibited the translation by rabbit reticulocyte lysate [56].

The proliferation of CD4(+) T cells and the production of IL-2, T cell growth factor were inhibited by artesunate. Moreover, the expression of cell surface protein CD25 (IL-2 receptor alpha chain) and CD69 on CD4(+) T cells were reduced. In addition, artesunate increased the production of IFN- $\gamma$ and IL- 4 under Th1 and Th2 skewed condition, respectively, and inhibited the activation of naïve T cell [57].

AAL and seeds treated mice induced the strongest DTH response, which decreases three-fold in IgG1 levels and increases 2-fold in IgG2a levels when compared to infected controls. Upon antigen recall in vitro, AALs and seeds enhanced lymphoproliferative response, IFN- $\gamma$ producing $\mathrm{CD} 4+$ and $\mathrm{CD} 8+\mathrm{T}$ lymphocytes and nitrite levels [58] (Fig. 1).

\section{The Role of Digestive Function}

A trypsin was purified from 4-day old germinated seeds of rice bean; the activity of the enzyme is a serine protease which benefits the digestive function [59]. ML which can promote the secretion of digestive juice in vivo and in vitro in intestinal canal rabbit, especially for the contraction of rabbit intestinal fatigue has an activation function. ML could adjust the amount of intestinal tract micro-flora in patients with irritable bowel syndrome and improve the clinical symptoms [60]. ML which impelled functions and intestines of hungry mice, promot-

Mechanism of Chinese Medicinal-ML for

Preventing and Treating GIT Diseases ed digestion for invigorating the function of the spleen [61]. The pathologic changes of gastric mucosa were improved greatly, and inflammatory degree in treated groups was significantly decreased compared to untreated group. It was found that amygdalin could reduce the activity of gastric pepsin and has significant effect in treating chronic gastritis and chronic atrophic gastritis [62]. It was found that amygdalin inhibited the acute gastric mucosa injury induced by restraint-cold stress, as well as improved the healing process of chronic gastric ulcer by acetic acid in rats and inhibited the formation of gastric ulcer in rats induced by pylorus ligature. Moreover, amygdalin plays a significant role in treating gastric ulcer [63].

\section{The Role of Secondary Metabolites}

Flour, bitter apricot seed, adzuki bean form the solid culture medium; while fresh juice of A. annua, X. sibiricum Patr, P. hydropiper form the liquid nutrient medium. They are suitable for different kinds of probiotic bacteria growth and provide adequate nutrition.

By morphology and molecular biology identification, 3 strains of fungi Aspergillus flavus, Penicillium chrysogenum and Cladosporium fungus were found in the ML, and some species were isolated and identified in ML samples including the bacteria Pantoea agglomerans, Staphylococcus haemolyticus, Enterobacter asburiae, Bacillus subtilis, Bacillus cereus, Pediococcus pentosaceus; the yeasts Hyphopichia burtonii, Debaryomyces hansenii, Pichia kudriavzevii and the filamentous fungi Mucor circinelloides, Mucor racemosus, Penicillium camembert, Aspergillus candidus $[11,64]$.

Yeast strains were isolated from fresh Massa Medicata Fermentata samples that sold in markets. After fermentation, the Massa Medicata Fermentata samples contained a variety of yeast species. Yeasts were the main microorganism of the fermentation process. The isolated strains Y1, Y3, Y4, Y5 were Cryptococcus albidus, Saccharomyces cerevisiae, Pichia kudriavzevii, Endomyces fibuligera, respectively [65].

Probiotic bifidobacteria, in combination with prebiotic carbohydrates, have documented positive effects on human health regarding gastrointestinal disorders and improved immunity, however, the selective routes of uptake remain unknown for most candidate prebiotics [66]. Stachyose can improve the intestinal environment, and regulate the function of the intestinal imbalance flora. 


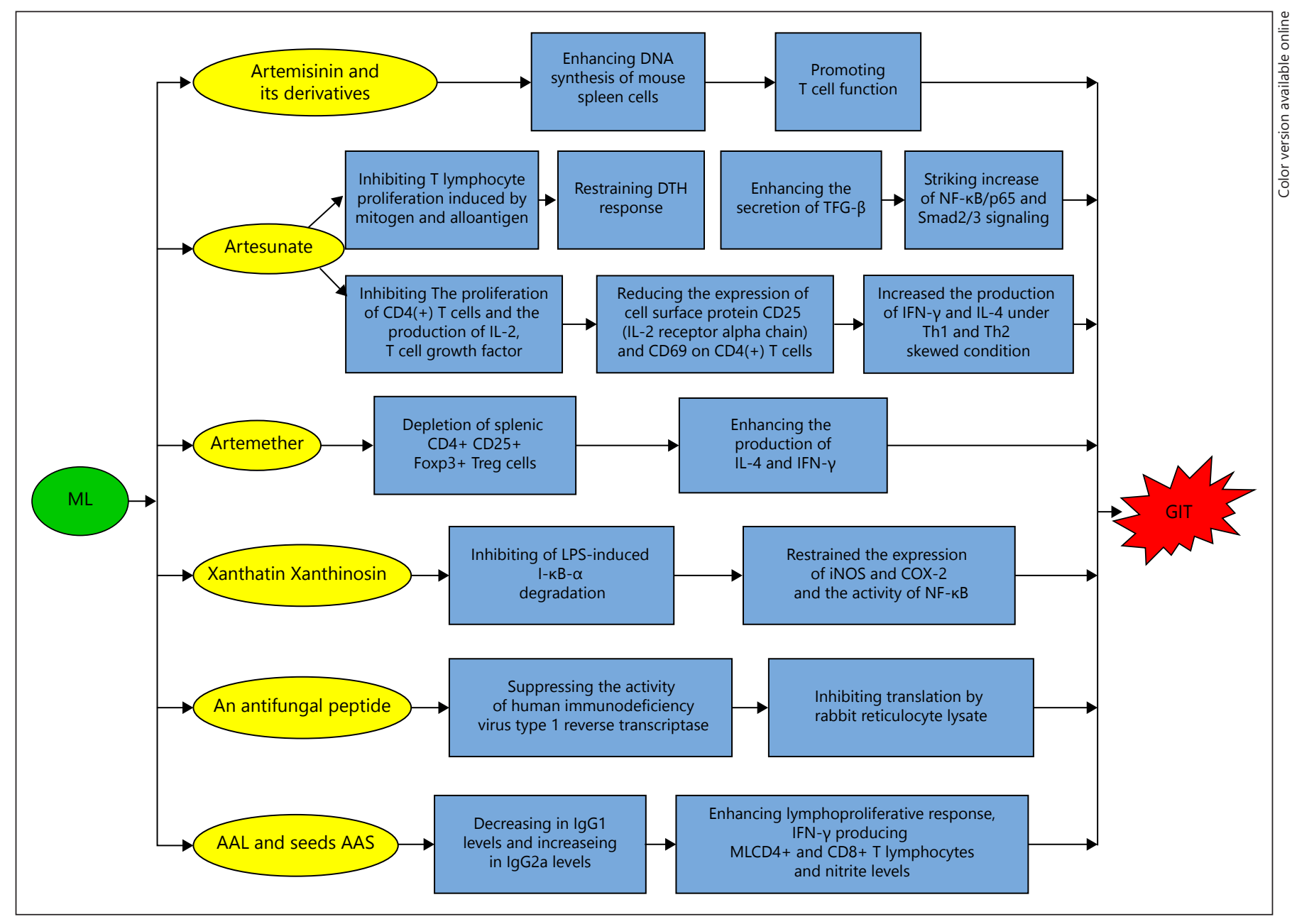

Fig. 1. The role of immune function of ML. ML, Medicated leaven; AAL, Artemisia annua leaves; AAS, Artemisia annua seeds; LPS, lipopolysaccharide; NF- $\mathrm{B} / \mathrm{p} 65$, nuclear transcription factor kappa B p65; IL-4, interleukin-4; GIT, gastrointestinal tract.

\section{Discussion}

With rapid development, the incidence of gastrointestinal diseases has also increased significantly. In 1612 A.D., ML was recorded in medicinal theory (Yao xinglun) as having an effect on gastrointestinal diseases. Although ML has been used for the treatment of gastrointestinal diseases for thousands of years, the system studies rarely explain its mechanism. In this review, we attempted to clarify the real reason for the magical efficacy of ML. A. annua, $X$. sibiricum, $P$. hydropiper together with flour, adzuki bean, and bitter apricot kernels help in the prevention and treatment of gastrointestinal diseases. In fact, these investigations clearly show that it has recently been a hot target of many research studies related to a strong relationship among the biological, chemical, pharmacological, and medical properties of these plants. Interestingly, studies indicate that ML has potential disease-modifying properties, including its well proven effects of antibacterial and antiviral effect, the mechanism of improving human immunity, antioxidant and anti-inflammatory activities, the role of digestive function and the role of its secondary metabolite.

In the clinical field, Shenqu oral liquid can accelerate the patient's recovery, relieve clinical symptoms, improve the patient's quality of life, safety, reliability, good taste, and achieve significant therapeutic effects, and has clinical application value [67].

After treatment the counts of Bifidobacterium were increased $(p<0.05)$ and Lactobacillus increased remarkably $(p<0.01)$ in patients of the Shenqu group. It could adjust the amount of intestinal tract microflora in pa- 
tients with irritable bowel syndrome and improve the clinical symptoms [68]. Therefore, it contributes not only to symptomatic improvement, but also plays an important role in the treatment of gastrointestinal diseases. ML may be the new hope for GIT diseases.

\section{Acknowledgments}

This work was supported by National Natural Science Foundation of China (Grant No.81073049); Science Foundation of Heilongjiang Province (Grant No. QC2017114); the Young Sci- ence Foundation of Department of Education (Grant No. UNPYSCT-2017222); Science Foundation of Heilongjiang Province of Administration of Traditional Chinese Medicine Technology (Grant No. ZHY16-089); Science Foundation of Heilongjiang Province Harbin City Technology Bureau (Grant No. 2016RAQXJ214), and Science Foundation of Heilongjiang Institute of Technology (Grant No. 2013BJ10).

\section{Conflict of Interest Statement}

The authors have no conflicts of interest.

\section{References}

1 Liu W, Liu Y: Youyou Tu: significance of winning the 2015 nobel prize in physiology or medicine. Cardiovasc Diagn Ther 2016;6:1-2.

2 Callaway E, Cyranoski D: Anti-parasite drugs sweep Nobel prize in medicine 2015. Nature 2015;526:7572.

3 Wang QH, Fu X, Wang CF, et al: The antimicrobial activity studying of Medicated leaven. China Assoc Chinese Med 2009:525-529.

$4 \mathrm{Li} \mathrm{B}, \mathrm{Li}$ J, Pan X, et al: Artesunate protects sepsis model mice challenged with Staphylococcus aureus by decreasing TNF-alpha release via inhibition TLR2 and Nod2 mRNA expressions and transcription factor NF-kappaB activation. Int Immunopharmacol 2010;10 344-350.

5 Jiang W, Li B, Zheng X, et al. Artesunate has its enhancement on antibacterial activity of $\beta$-lactams via increasing the antibiotic accumulation within methicillin-resistant Staphylococcus aureus (MRSA). J Antibiot (Tokyo) 2013;66:339-345.

6 Marinas IC, Oprea E, Chifiriuc MC, et al: Chemical composition and antipathogenic activity of Artemisia annua essential oil from Romania. Chem Biodivers 2015;12:15541564 .

7 Ivarsen E, Fretté XC, Christensen KB, et al: Bioassay-guided chromatographic isolation and identification of antibacterial compounds from Artemisia annua L. that inhibit clostridium perfringens growth. J AOAC Int 2014;97: 1282-1290.

8 Kim WS, Choi WJ, Lee S, et al: Anti-inflammatory, antioxidant and antimicrobial effects of artemisinin extracts from Artemisia annua L. J Physiol Pharmacol 2015;19:21-27.

9 Islamuddin M, Chouhan G, Tyagi M, et al: Leishmanicidal activities of Artemisia annua leaf essential oil against Visceral Leishmaniasis. Front Microbiol 2014;5:626.

10 Cumanda J, Marinoni G, Bemardi M, et al: New sesquiterpenes from Xanthium catharticum. J Nat Prod 1991,54:460-465.
11 Jia D, Huang C, Liu Y, et al: Identification and Isolation of microorganisms from Medicated leaven during its production. Mod Chin Med 2016;18:357-361.

12 Tsankova ET, Trendafilova AB, Kujumgiev AI, et al: Xanthanolides of Xanthium italicum Moretti and their biological activity. Z Naturforsch C 1994;49:154-155.

13 Shi YS, Liu YB, Ma SG, et al: Bioactive Sesquiterpenes and Lignans from the fruits of Xanthium sibiricum. J Nat Prod 2015;78:15261535 .

14 Chen WH, Liu WJ, Wang Y, et al: A new naphthoquinone and other antibacterial constituents from the roots of Xanthium sibiricum. Nat Prod Res 2015;29:739-744.

15 Huang JQ, Zheng GF, Sumanac K, et al: Metaanalysis of the relationship between cagA seropositivity and gastric cancer. Gastroenterology 2003;125:1636-1644.

16 Goswami S, Bhakuni RS, Chinniah A, et al: Anti-Helicobacter pylori potential of artemisinin and its derivatives. Antimicrob Agents Chemother 2012;56:4594-4607.

17 Yiğit D, Yiğit N, Mavi A: Antioxidant and antimicrobial activities of bitter and sweet apricot (Prunus armeniaca L.) kernels. Braz J Med Biol Res 2009;42:346-352.

18 Duraipandiyan V, Indwar F, Ignacimuthu S: Antimicrobial activity of confertifolin from Polygonum hydropiper. Pharm Biol 2010;48: 187-190.

19 Kubo I, Fujita K: Naturally occurring antiSalmonella agents. J Agric Food Chem 2001; 49:5750-5754.

20 Efferth T, Marschall M, Wang X, et al: Antiviral activity of artesunate towards wild-type, recombinant, and ganciclovir-resistant human cytomegaloviruses. J Mol Med 2002;80: 233-242.

21 Efferth T, Davey M, Olbrich A, et al: Activity of drugs from traditional Chinese medicine toward sensitive and MDR1-or MRP1-overexpressing multidrug-resistant human CCRFCEM leukemia cells. Blood Cells Mol Dis 2002;28:160-168.
22 Qian RS, Li ZL, Yu JL, et al: The immunologic and antiviral effect of Qinghaosu. J Tradit Chin Med 1982;2:271-276.

23 Romero MR, Serrano MA, Vallejo M, et al: Antiviral effect of artemisinin from Artemisia annua against a model member of the Flaviviridae family, the bovine viral diarrhoea virus (BVDV). Planta Med 2006;72:1169-1174.

24 Efferth T, Marschall M, Wang X, et al: Antiviral activity of artesunate towards wild-type, recombinant, and ganciclovir-resistant human cytomegaloviruses. J Mol Med 2002;80: 233-242.

25 Kaptein SJ, Efferth T, Leis M, et al: The antimalaria drug artesunate inhibits replication of cytomegalovirus in vitro and in vivo. Antiviral Res 2006;69:60-69.

26 Lee SH, Kim B, Oh MJ, et al: Persicaria hydropiper (L.) spach and its flavonoid components, isoquercitrin and isorhamnetin, activate the $\mathrm{Wnt} / \beta$-catenin pathway and inhibit adipocyte differentiation of 3T3-L1 cells. Phytother Res 2011;25:1629-1635.

27 Shapira MY, Resnick IB, Chou S, et al: Artesunate as a potent antiviral agent in a patient with late drug-resistant cytomegalovirus infection after hematopoietic stem cell transplant. Clin Infect Dis 2008; 46: 1455-1457.

28 Ames BN: Dietary carcinogens and anticarcinogens. Oxygen radicals and degenerative diseases. Science 1983;221:1256-1264.

29 Ness AR, Powles JW: Fruit and vegetables, and cardiovascular disease: a review. Int J Epidemiol 1997;26:1-13.

30 Poulsen HE, Prieme H, Loft S: Role of oxidative DNA damage in cancer initiation and promotion. Eur J Cancer Prev 1998;7: 9-16.

31 Wang H, Cao G, Prior RL: Total antioxidant capacity of fruits. J Agric Food Chem 1996;44: 701-705.

32 Kris-Etherton PM, Hecker KD, Bonanome A, et al: Bioactive compounds in foods: their role in the prevention of cardiovascular disease and cancer. Am J Med 2002;113(suppl 9B): 71S-88S.
Mechanism of Chinese Medicinal-ML for Preventing and Treating GIT Diseases
Digestion 2020;101:659-666 DOI: $10.1159 / 000493424$ 
33 Efferth T, Briehl MM, Tome ME: Role of antioxidant genes for the activity of artesunate against tumor cells. Int J Oncol 2003;23:12311235.

34 Peng ZF, Strack D, Baumert A, et al: Antioxidant flavonoids from leaves of Polygonum hydropiper L. Phytochemistry 2003;62:219228.

35 Haraguchi $\mathrm{H}$, Hashimoto K, Yagi A: Antioxidative substances in leaves of Polygonum hydropiper. J Agric Food Chem 2002;40:13491351.

36 Kiem PV, Nhiem NX, Cuong NX, et al: New phenylpropanoid esters of sucrose from Polygonum hydropiper and their antioxidant activity. Arch Pharm Res 2008;31:1477-1482.

37 Jayawardana BC, Hirano T, Han KH, et al: Utilization of adzuki bean extract as a natural antioxidant in cured and uncured cooked porksausages. Meat Sci 2011;89:150-153.

38 Yang HY, Chang HK, Lee JW, et al: Amygdalin suppresses lipopolysaccharide-induced expressions of cyclooxygenase- 2 and inducible nitric oxide synthase in mouse BV2 microglial cells. Neurol Res 2007;29:59-64.

39 Hwang HJ, Lee HJ, Kim CJ, et al: Inhibitory effect of amygdalin on lipopolysaccharide-inducible TNF-alpha and IL-1beta mRNA expression and carrageenan-induced rat arthritis. J Microbiol Biotechnol 2008;18:16411647.

40 Chukwurah PN, Brisibe EA, Osuagwu AN, et al: Protective capacity of Artemisia annua as a potent antioxidant remedy against free radical damage. Asian Pac J Trop Biomed 2014; 4(suppl 1):S92-S98.

41 Li YJ, Guo Y, Yang Q, et al: Flavonoids casticin and chrysosplenol D from Artemisia annua $L$. inhibit inflammation in vitro and in vivo. Toxicol Appl Pharmacol 2015;286:151158.

42 Dilshad E, Zafar S, Ismail H, et al: Effect of Rol genes on polyphenols biosynthesis in Artemisia annua and their effect on antioxidant and cytotoxic potential of the plant. Appl Biochem Biotechnol 2016;179:1456-1468.

43 Kim KE, Ko KH, Heo RW, et al: Artemisia annua leaf extract attenuates hepatic steatosis and inflammation in high-fat diet-fed mice. J Med Food 2016;19:290-299.

44 Lai L, Chen Y, Tian X, et al: Artesunate alleviates hepatic fibrosis induced by multiple pathogenic factors and inflammation through the inhibition of LPS/TLR4/NF-kB signaling pathway in rats. Eur J Pharmacol 2015;765: 234-241.
45 Song Y, Desta KT, Kim GS, et al: Polyphenolic profile and antioxidant effects of various parts of Artemisia annua L. Biomed Chromatogr 2016;30:588-595.

46 Yang Y, Yu T, Jang HJ, et al: In vitro and in vivo anti-inflammatory activities of Polygonum hydropiper methanol extract. J Ethnopharmacol 2012;139:616-625.

47 Ren SZ, Chen J, Su WQ, et al: Effect of Fengliao extract on mice with experimental ulcerative colitis. Chin J Pharmacol Toxicol 2016;30:344-349.

48 Yang SX, Xie SS, Gao HL, et al: Artemisinin and its derivatives enhance $\mathrm{T}$ lymphocytemediated immune responses in normal mice and accelerate immunoreconstitution of mice with syngeneic bone marrow transplantation. Clin Immunol Immunopathol 1993;69:143148.

$49 \mathrm{Li} \mathrm{T}$, Chen H, Yang Z, et al: Evaluation of the immunosuppressive activity of artesunate in vitro and in vivo. Int Immunopharmacol 2013;16:306-312.

50 He SP, Tan GY, Li G, et al: Development of a sensitive monoclonal antibody-based enzyme-linked immunosorbent assay for the antimalaria active ingredient artemisinin in the Chinese herb Artemisia annua L. Anal Bioanal Chem 2009;393:1297-1303.

51 Ferreira JF, Janick J: Immunoquantitative analysis of artemisinin from Artemisia annua using polyclonal antibodies. Phytochemistry 1996;41:97-104.

52 Ferreira JF, Luthria DL, Sasaki T, et al: Flavonoids from Artemisia annua L. as antioxidants and their potential synergism with artemisinin against malaria and cancer. Molecules 2010;15:3135-3170.

53 Farsam V, Hassan ZM, Zavaran-Hosseini A, Noori S, Mahdavi M, Ranjbar M: Antitumor and immunomodulatory properties of artemether and its ability to reduce CD4+ CD25+ FoxP3+ T reg cells in vivo. Int Immunopharmacol 2011;11:1802-1808.

54 Lee CL, Huang PC, Hsieh PW, et al: (-)-Xanthienopyran, a new inhibitor of superoxide anion generation by activated neutrophils, and further constituents of the seeds of Xanthium strumarium. Planta Med 2008;74: 1276-1279.

55 Yoon JH, Lim HJ, Lee HJ, et al: Inhibition of lipopolysaccharide-induced inducible nitric oxide synthase and cyclooxygenase- 2 expression by xanthanolides isolated from Xanthium strumarium. Bioorg Med Chem Lett 2008; 18:2179-2182.
56 Ye XY, Ng TB: A new antifungal peptide from rice beans. J Pept Res 2002;60:81-87.

57 Lee SH, Cho YC, Kim KH, et al: Artesunate inhibits proliferation of naïve CD4(+) T cells but enhances function of effector T cells. Arch Pharm Res 2015;38:1195-1203.

58 Islamuddin M, Chouhan G, Farooque A, et al: Th1-biased immunomodulation and therapeutic potential of Artemisia annua in murine visceral leishmaniasis. PLoS Negl Trop Dis 2015;9:e3321.

59 Basu PS, Biswas C, Majhi R, et al: Serine proteinase from rice bean. Indian J Biochem Biophys 1996;33:491-497.

60 Zhuang YH, Yang CH, Yang XD, et al: Study on the microecological changes and curetive effects of irritable bowel syndrom by Chinese drug "Shenqu". Chinese J Microecol 2005; 17: 41-43.

61 Nan Y, Zhu C: Studies on the technological process for preparing medicated leaven. Zhongguo Zhong Yao Za Zhi 1992;17:471474.

62 Deng JY, Li YM, Lu LL: Effect of amygdalin on chronic gastritis and chronic atrophic gastritis. J China Pharmaceutical University 2002;33:45-47.

63 Cai Y, Li YM, Zhong L: Effect of amygdalin on gastric ulcer in experimental models. J China Pharmaceutical University?2003;34:254-256.

64 Wang QH, Fu X, Kuang HX, et al: Study on isolation and identification of fungi in Medicated leaven. Chinese J Exp Tradit Med Formulae 2014;20:122-127.

65 Zhang L, Gao W, Wang H: Identification of microorganism from traditional Chinese medicine Massa Medicata Fermentata. Zhongguo Zhong Yao Za Zhi 2012;37:19281931.

66 Andersen JM, Barrangou R, Hachem MA, et al: Transcriptional analysis of oligosaccharide utilization by Bifidobacterium lactis Bl-04. BMC Genom 2013;14:312.

67 Zhang JH: Clinical study on the treatment of functional dyspepsia in children with Shenqu oral liquid. World Latest Medicine Information 2018;18:123-124

68 Zhang YH, Yang CH, Yang XD, et al: Study on the microecological changes and curetive effects of irritable bowel syndrom by Chinese drug "Shenqu". Chinese J Microecol 2005;17: 41-43. 